\title{
The Development of Emotional Concepts in Autism
}

\author{
Christiane Bormann-Kischkel, Markus Vilsmeier \\ and Beate Baude
}

\begin{abstract}
Forty-one high-functioning individuals with autism between the ages of 7 and 36 and an age and intelligence matched comparison group were investigated in their ability to recognise emotions in photographs. A colour identification task served as control condition. The autistic group was significantly impaired on the emotions task only. There was no substantial difference between groups in the structures underlying their emotional concepts (pleasantness and arousal). However, there is a trend for the autistic group to rely on other strategies in the recognition of emotions than the comparison group. These strategies may be insufficient in the appreciation of facial expressions.
\end{abstract}

Keywords: Autism, emotion, recognition, emotional concepts, high-functioning Abbreviations: AID: Allgemeines Intelligenzdiagnostikum, MDS: multidimensional scaling, PDD: pervasive development disorder

\section{Introduction}

Numerous studies on the comprehension of emotions have shown that people with autism are impaired in recognising and understanding emotional expressions. The comprehension of emotional expressions has mostly been investigated with facial expressions. Procedures such as recognition of facial expressions from photographs or videos, labelling expressions in pictures or tape recordings, picture to picture or picture to sound matching, matching pictures of facial expressions to a situational context, or combinations of these tasks have been employed. These studies varied in many ways, such as age of the autistic subjects (preschool age to adolescence), kind of control group (normally intelligent or mentally retarded children), matching variables (verbal or nonverbal measures, chronological or mental age) and experimental procedures. Because of this methodological heterogeneity it is perhaps not surprising that some authors report contradictory results. Hobson (1991) gave a detailed overview of this research and considered

\section{Accepted manuscript received 3 March 1995}

Requests for reprints to: Christiane Bormann-Kischkel, Bezirkskrankenhaus Regensburg, Klinik für Kinder- und Jugendpsychiatrie, Postfach 93042, D-93042 Regensburg, Germany. 
the various medhodological and concepual pobblems involved. He concluded that the body of the evidence is in favour of a disturbed comprehension of emotional expressions in autism, although the tesults are not always in agreement. His conclusions have been confirmed and extended by four other studies that investigated the comprehension of emotions in more elaborate ways. The fact that emotional expressions in facial photographs are less salient to children with autism than, for instance, hats (Jemnings, 1973; Weeks \& Hobson, 1978) and wigs (BormannKischikel, I99()) has been contirmed by behaviour observations in natural situations. Preschoolers with autism were less attentive towards an adult expressing distress, fear or disconnfor than mentally retarded and nomal children. They appeared to ignore or nol to notice the adult but were more engaged with other activities, such as toy play (Sigman, Kasari, Kiwon \& Yimiya, 1992). Fein, I ncci, Braverman and Waterhouse (1992) compared the ability of 15 children with pervasive developmental disorders (PIDI) to match fotir different emotions to an appropriate context (e.g. scared-child lalling off a ladder). Although they found no difference between the PIDI)-group and a comparison group of nomal children, the children with PIDD) were slightly but significantly better on a nonsocial control task equated with the emotions task for difficuly. A similar result was reported by (apps, Yirmiya and Sigman (1992). They compared the ability of nonretarded children with autism to understand simple emotions, such as happiness and sadness, with their performance at complex ones, such as pride and embarrassment. Happiness and pride share features of pleasantness but differ in locus of responsibility and controllability. A similar distinction can be drawn for sadness and embarrassment The performance of children with autism was quantilatively not very different fiom that of the normal children, but they required more time and prompts to talk about the complex emotions, and they did not differentiate sadness from embarrassment on the basis of locus of comtrollability. Many of them reported experiences as embarrassing which had external causes and were uncontrollable by themselves.

Emotions and their contribution to empathetic behaviour were studied in highfunctoning children with autism by Yiminiya, Sigman, Kasari and Mundy (1992). They presented their participants with videotaped segments of stories with a protagonist experiencing one of five emotions (happiness, anger, pride, sadness and fear). The children had to label each emotion the protagonist experienced state their own feeling, and to describe why they felt so. Although the autistic children did quite well on all these tasks, heir performance was inferior to the normal comparison children. To sum up, children with autism exhibit peculiarities in the way m which they deal with emotional expressions. Although high-functioning mdividuals appear to understand simple emorions such as happiness, anger, sadness and fear, theyare less competent with more complex ones and have more problems relating them to a context.

A characteristic of many if not all studies on the comprehension of emotions is the small magnitude of e fects, especially with high-functioning suljects. This has been taken as an argument against a core deficil of the comprehension of emotions in autistic children. A small effect often indicates a large overlap in distributions. Alhough this does not qualify the task under consideration to be used for diagnostic discriminations, it cannot be interpreted as a nonexistence of differences. A small effect may also indicate an impaiment as opposed to complete inability. For instance, autistic children may develop compensatory strategies to overcome their handicap. Hobson, (Ouston and 1 .ee (1988) have shown that autistic adolescents use other strategies than mentally retarded adolescents to identify facial expressions. The autistic persons' handicap became obvious only when the task grew more difficult. In two other studies, it was noted hat children with autism were more easily confused than control children in sorting picures of tacial expressions by items with perceptual (but not conceptual) similarity (Bomann-Kischkel, 1990) Ozonoff, Pennington \& Rogers, 1991). The notion of aulism as a "logico-alfective state" proposed by llermelin and ()' Comnor (1985) provides another explanation along these lines. They suggest that high-functioning autistic children may overcome part of their problems by using cognitive or intellectual routes to process emotions. Because these strategies are sub-optinal, however, they cannot fully compensate for the deficit.

Another reason for a lailure to tind differences between groups may be the smal number of emotions studied (mostly only three or four). Extending the number of emotional expressions would inprove the basis of comparisons. A series of interesting studies by Russell ( 1983) and Bullock and Russell $(1984,1985)$ provides a method to deal with these problems. They studied emotion recognition in normal preschool children and adults by using nine pictures of emotional expression and 15 different emotion terms, some of which were synonyms, e.g. angry-niad. (Because this was an American study, angry and mad were considered as synonyms.) They found that normal preschool children were inferior to older children and adults in their comprehension of emotion terms. llowever, a multidimensional scaling procedure (MDS) revealed that the structure underlying the responses was identical for all age groups. Young children organised emotional concepts by the underlying two dimensions "pleasure vs displeasure" and "high vs low arousal" just a adults did. This was also true for German children and adults (Bormann-Kischkel, Hildebrand-Pascher \& Steglauer, 199()). The advantages of this approach are twofold: it has been tested with several groups of normal children and adults, thus providing a wide base for comparisons. Furthermore, the multidimensional scaling procedure allows for an investigation of strucures underlying the children's responses and may provide information on the strategies used.

In order to rule out the influence of unspecific factors, such as attention problems, we devised a control experiment which was identical in task demands and response format to the first one but different in content. The children were presented with small colour plates of medium satiation values, which they had to match to differem colour names. The results of a pilot study with normal 5-year-old children and adults (Kulzer, unpublished diploma's thesis) indicate that this material shows some parallels to the emotion task: the children made more errors than the adults, but their responses were not randomly dispersed across the spectrum. Colours adjacent to each other according to the colour circle were more easily confused than colours further apart. The structure underlying all subjects' responses was the same, namely, a colour circle with the dimensions "red-green" and "blue-yellow". 
Because we assume that there is a specific deficit in understanding emotional expressions in autism, we expect autistic children to be impaired in the comprehension of emotion terms, but not in the comprehension of colour terms. Further, if persons with autism use strategies in the comprehension of emotions which differ from those of persons without autism, the multidimensional scaling procedures should provide different solutions for the emotion terms only, but not for the colour terms.

\section{Mechod}

suljects

The autisile group consisted of $t 1$ individuals with altusm who contormed to Rutter's (1978) riteria in showing characteristic features in their social, language and communicative behaviour. All exhibited (more or less marked) stereotypies and/or special interests All subjects had been diagnosed prior to their participation in this study by a child psychiatrist or by an experienced clinica psychologist not affiliated with this study. For an additional control, 21 cases were checked according to DSMI-III-R criteria. All these subjec is fulfilled the criteria for early infantile autism. No differences were noticed between those subjects with DSM-III-R diagnoses and those without. Three children were inpatients of a child psychiatry department in Munich, 15 children and adults were contacted through the German national parents' association in Munich. Many of them were patients at the child psychiatry institution. Twenty-one participants were tested at a counselling centre for autistic children and adolescents in V'ienna. A nonverbal test of intelligence (Raven's Coloured Progressive Matrices or Standard Progressive Matrices 1987), a vocabulary test (subtest 6: "Synonyme finden" [Synonyms] from "Adaptives Intelligenz Diagnostikum". AID (Kubinger \& Wurst, 1991), a screening for colour blindness (Dvorine, 1963), and the two experimental tasks were administered to each subject. The age of the subjects varied from 7;0 to 35; 4 years. All subjects were able to follow verba instructions and, with one exception, were verbal.

The control group consisted of 41 children and adolescents. They were individually matched by age and Raven's raw scores but not by their performance on the vocabulary test. Because of the heterogeneous I ( $)$ and age in the autistic group, the control group comprises a mixed sample. Criteria for selecting participants for the comparison group were their correspondence in age as well as IQ score to one member of the group with autism, and a history of developmental speech and language disorder or multiple developmental delay. Care was taken that individuals with autistic features were excluded, either by prior diagnosis or by clinical impression. Both authors, whe carried out the testing ( $($. B.-K. and B. B.), have had substantial experience in working with autistic children, so that it is unlikely to have included a nondiagnosed person with autism. Because of the very high IQ scores of three autistic participants, the criterion of a developmental disorder had to be given up in these cases, since no corresponding subjects could be found. lnstead, three normal participants, matching in age and $I()$, were selected.

Of the comparison group, 15 children had a diagnosis of developmental speech and language disorder or of multiple developmental delay (including language, reading and motor development). Three children were severely dyslexic, eight were learning disabled (no further specification), and 12 mentally retarded (two with Down's syndrome, 10 without further diagnosis). In addition, two normal children and one normal adult from the technical staff of the University of Regensburg participated as comparison subjects. They were recruited from the same child psychiatry unit as the autistic children $(N=8)$, from a special school for children with speech and language disorders $(N=5)$, from two schools for learning disabled pupils $(N=12)$, two schools for memtally retarded children $(N=12)$, and from normal schools $(N=3)$. Informed consent was obtained from all parents and from the adult participants themselves. Age, $1 Q$ and vocabulary scores are presented in Table 1. It should be noted that one participant from the comparison group had to be dropped in the Colour Task (see below), because he turned out to be colour-blind on the screening for colourblindness.
Table 1. Means and standard deviations $(S I)$ ) of age, $1 Q-$ and vocabulary-scores for the autistic and control group

\begin{tabular}{|c|c|c|}
\hline & $\begin{array}{l}\text { Auistic Group } \\
\qquad(N=41)\end{array}$ & $\begin{array}{c}\text { Control Group } \\
(N=+1)\end{array}$ \\
\hline Age* & 173.4 & 161.4 \\
\hline$S D)$ & 82.6 & 65.2 \\
\hline Raven & 86.8 & 85.9 \\
\hline SI) & 24.7 & 23.8 \\
\hline All)-Synenyms! & $f(1) .1$ & $t(i .9$ \\
\hline SI) & 18.7 & 221 \\
\hline
\end{tabular}

*Months, $\nmid \mathrm{I}\left(\mathrm{Q}\right.$-scores, ${ }_{+}^{\dagger} \mathrm{T}$-scores.

Material

Emotion lask. The satne nine prenues as in Bulleck and Kussell (lyst) were used. These photus depict nine different female models posing different emotions, six of which (happy, angry, sad afraid, disgusted, surprised) are from the Ekman and Friesen (1975) set. The remaining three (excited, calm, sleepy) pictures have been addled by the aunhors*. We followed Bullock and Russell: (1984) procedure except for using Geman emotion terms. The picures were $8.5 \times 12 \mathrm{~cm}$ in size mounted on cardboards of $12 \times 17.5 \mathrm{~cm}$ and laminated for protection. Exemplars of all photos have been published in Bullock and Russell (1984).

Colour Task. For the control experiment, subjects were presented with 10 colour plates. These were small chips with a diameter of $1.0 \mathrm{~cm}$, which were selected from the "Roth $28 \mathrm{Hue}$ Test" (Koth noyear viven). This test consists of 28 nonlucent colour plates with equi-distant hue values disuributer across the colour circle. We selected 10 out of these 28 plates with five principal hues $(=$ red, yellow green, blue, purple) and their five intermediate combinations (orange, bluish green, etc.). These 10 hues divide the colour circle into 10 equal regions. Brightness and saturation of the plates ari medium (-/5/5 according to the Munsell notation). The $1($ ) plates are equidistant in their hues (nim intermediate steps) with one exception (six intermediate steps between chips 10 and 16 ). The Rot chiffres of the plates are $1,10,16,25,34,43,52,61,7()$ and 79 . The plates were labelled as red orange, yellow, olive or yellow-green, green, blue-green, urquoise, blue, violet, and pink or red-blue respectively, by 30 adulis not involved further in this study. It should be noted that although th hues were the most typical ones for the respective colour regions, not all plates were prototypes o the colour terms. This was so, because lightness (= value, $V$ ) and saturation (= chroma, $C$ ) were a medium levels. For a prototypical red, yellow, blue, etc. more satiated hues would have been required Our decision to use colours of medium satiation was based on two considerations: The Munsel colour solid is not symmetrical with regard to satiation but varies depending on the hue and lightnes of a colour. Using the most satiated colours would thus have implied a difference in satiation acros hues. Further, we auticipared that it might be hard to elicit second or third choices from hight satiated colours. Confusions among hues and overexiensions of colour terms are more likely to occu with nonprototypical category members (Heider, 1971; Rosch, 1975). Although the Munsell systen is a pragmatically devised colour scheme, its logic of construction with some limitations correspond to a psychological system of colour perception (Indow, 1988.

Procedure

All tasks were adnuinistered mone on tho sesslons, always in the sanne order. The finst sessio included the Colour Task, the Emotion Task, the screening for colour blindness and a test of auditor

*We wish to express our gratitude to Merry Bullock and James Russell who kindly provided "I with the stimulus material and all the information we needed. 
emotion recognition, which will not be dealt with further in this paper. In the second session, the I(2) and vocabulary tests were presented. Total testing time varied between 1.5 and 2.5 hours. № attempt was made to counterbalance the experimental conditions, because this would have required a within-yroup matching by age and intelligence, which would have imposed too many restrictions on the selection of participants

For the Emotion Task, all pictures were antanged in tront of a child, mostly in a $3 \times 3$ arrangement The experimenter asked the child to hand her a picture of a woman who was, e.g. happy. Without replacing this picture the child was asked to select anuther one, and finally a third one ("And who else is happy?"). After a child had made three choices, all pictures were put back, the cards were rearranged, and lie next emotion term was presented accordingly. Sixteen different emotion terms were used so that a maximum score of 16 could be obtained. Together with their translations, the an be found in Appendix A (for turther details, see Bormann-Kischkel $t$ al., 1990). If children efused to make a second or thind choice they were not forced co do so. However, this happened in less than $5 \%$ of all stimuli. The Colour Task was presented accordingly. Here, the maximum score was 17

\section{Results}

\section{Fiist ihuices}

For some emotions and colours, synonyms were used, because in our previous studies both terms had been produced with almost equal fiequencies. The maximum number of correct lirst choices was therefore 16 for the emotion terms and 15 for the colour names. Although all participants were presented with 17 colour terms, the terms oliv [olive] and ocker [ochre] were dropped from the analysis because it became apparent during testing that these colour words were unknown to many children. ( )wing to an experimenter error; some of the children got prompts from one experimenter; while others (tested by another experimenter) did not. Although the results reported subseguently did not differ; when both terms are included, we decided to onit these colour names fiom the andysis of the correct first choices.

()n the Emotion Task the autistic group was correct on the average on 6.9 emotion terms, the comparison group on 8.4 terms. On the Colour Task, the average correct scores were 10.5 for the autistic group and 10.4 for the comparison group) (see Figs. 1 and 2). An analysis of covariance with vocabulary as a covariate revealed no overall difference between groups $\left(\mathrm{F}_{78,1}=.88, p=.35()\right)$, a significant effect of task $\left(F_{7 y}=6.8(), p=.(011)\right.$, and a significant group by task interaction $\left(\mathrm{F}_{7 y, i}=6.8(), p=.011\right)$. The intluence of the covariate (vocabulary) is highly significant with a B-weight of . $t(t)(t=4.6(), p<.(0)])$. A posteriori comparisons for each task (ANO)VAS with vocabulary as covariate) show that both groups differ significantly on the Enotion Task $\left(F_{i y 1}=7,() 3, j=.(1)(0)\right.$, but not on the Colour Task $\left(F_{78,1}=.94\right.$, $p=.336)$

\section{Multiple regressions}

Given the large ranges of age and (C) in our sanples, it is conceivable that these variables, in addirion to vocabulary, exerted an influence upon the tasks studied. Moreover, we were interested in the relative contribution of these factors to each group. We therefore, calculated multiple regressions for each task and group

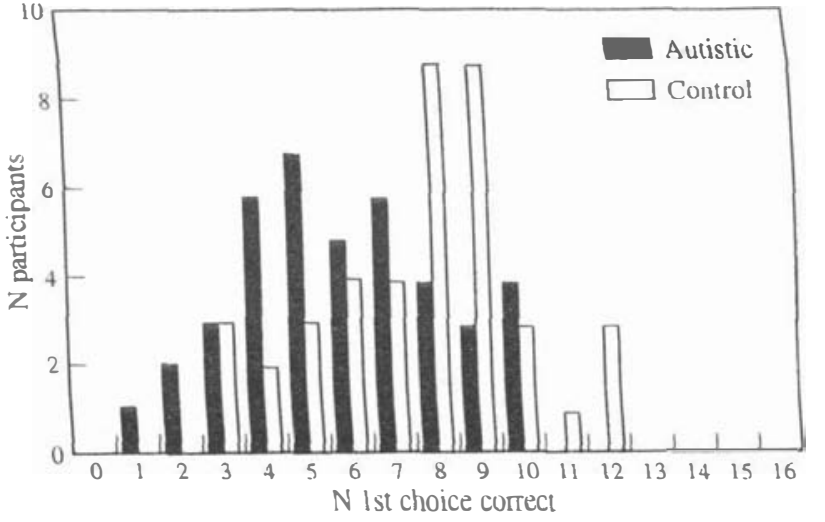

Fig. 1. Distribution of scores on the Entotion Task.

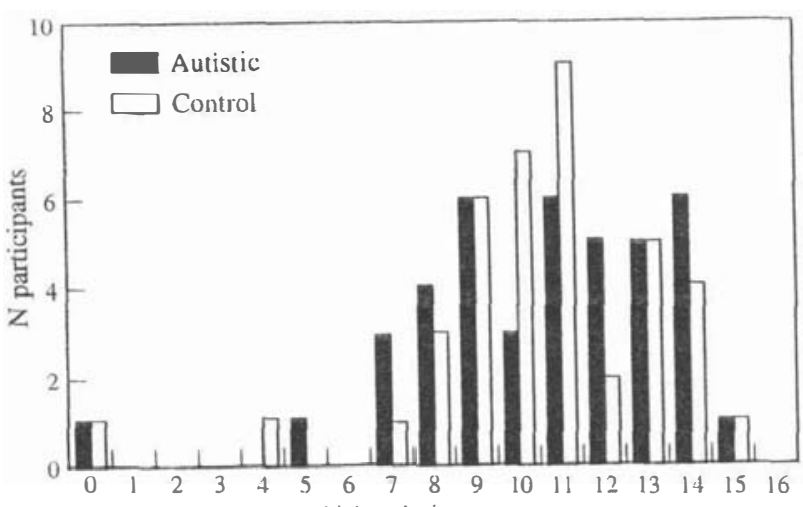

$\mathrm{N}$ lst choice correct

Fig. 2. Distribution of scores on the Colour 1 ask.

separatively. On the Emotion Task, different variables influence each group. The score of the autistic group is significantly influenced by the vocabulary score only $(B=.43 ; t=2.96, p=.(0) 5)$, while the comparison group is influenced by their IQ scores only $(B=45 ; t=3.12, p=.(0)(3)$. No other variables are of significant influence. On the Colour Task, the vocabulary score exerts the greatest influence upon the On the Colour Task, the vocabulary score exerts the gutistic group: $\beta=.6($ ) $; t=4.72$, $\phi<.001$; comparison group: $\beta=.42 ; t=2.98, p=.0(0.51)$. Age contributes to the correct colour choices of the comparison group only $(B=.34 ; t=2.42, p=.021)$. The contribution of all remaining variables to the regression equation again is nonsignificant

\section{Single colour and emotion terms}

With one exception, the correct first choices for each emotion term were above chance for both groups (binomial distribution with a priori probability $p=1 / 9$ ). 
The exception was the term entsetzt [territied], which buth groups did not associate with the standard picture D. Instead, there was a shift in focus to picture $C$ [surprised]. The control group was signiticantly superior to the autistic group on the terms zornig [angry] $\left(\chi^{2}=11.4, p<.01\right)$ and erstaunt [astonished] $\left(\chi^{2}=3.96, p<.05\right)$ There was a trend for the comparison group to be better on uiberrascht [surprised] $\left(\chi^{2}=2.71, p<.10\right)$, erschreckl [scared] $\left(\chi^{2}=3.47, p<.10\right)$, and wütend [angry] $\left(\chi^{2}=3.17, p<.10\right)$.

Both groups were above chance on their first choices on all colour terms (binomial distribution with a priori probability of $p=1 / 10)$. Despite the lack of an overall difference between groups, the autistic subjects were superior to their comparison group on the colour name gellgrïn [yellow-green] $\left(\chi^{2}=4.73\right.$, $\left.p_{l y-1}<.05\right)$.

Structure of emotions.

The antistic participants made more emors than the control participants. The next question was whether the structure underlying the responses is different for the autistic subjects as compared to the control subjects. We therefore computed a multidimensional scaling analysis (MDS). In this analysis, similarities between stimuli (pictures or chips in our case) are converted into geometrical distances. Stimuli similar to each other will also be spatially close to each other in a geometrical representation. Varying the number of dimensions of the space will lead to different colutions. The configuration representing the data best according to a goodnessof-fit criterion is selected for interpre tation. The dimensions describing the space in which the data are depicted represent the underlying structure of the subjects' choices and have to be interpreted psychologically. The co-occurrence of the frequency of two pictures among the three choices to a given emotion term can be regarded as an indirecl measure of similarity. From these frequencies a matrix of similatity was computed by determining how of ten particular pairs of photographs were included among a subject's three choices. This matrix was then subjected to

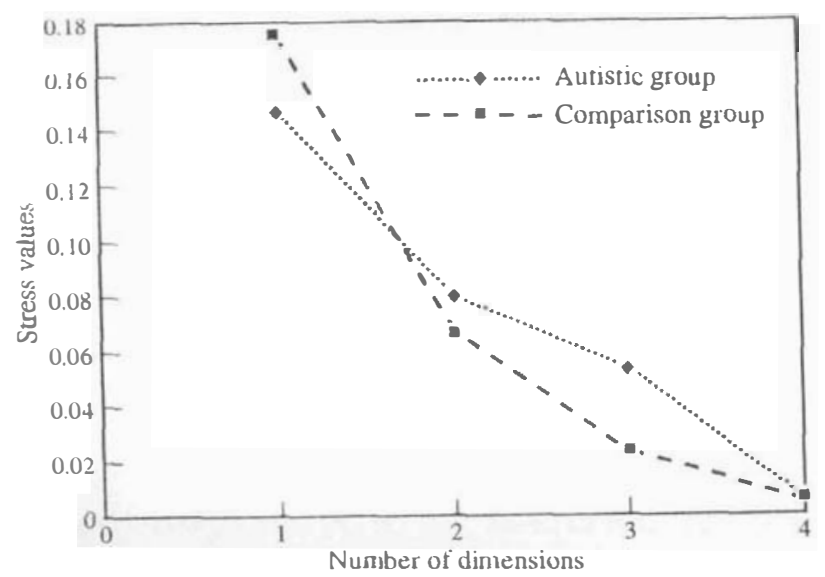

Fig. 3. Suress values of the multidimensiond scaling solutions for the emotional expressions. a nonmetric MDS (SPSS-X, 1991). The "stress value", which is a measure for the amount of variance left unexplained by a given solution, serves as a goodness-offit criterion. Because a model with too many dimensions is difficult to interpret, one usually prefers the $n$-dimensional solution which shows the sharpest decrease in stress from $n-1$ to $n$ dimensions. This is the two-dimensional solution for both groups (Fig. 3).

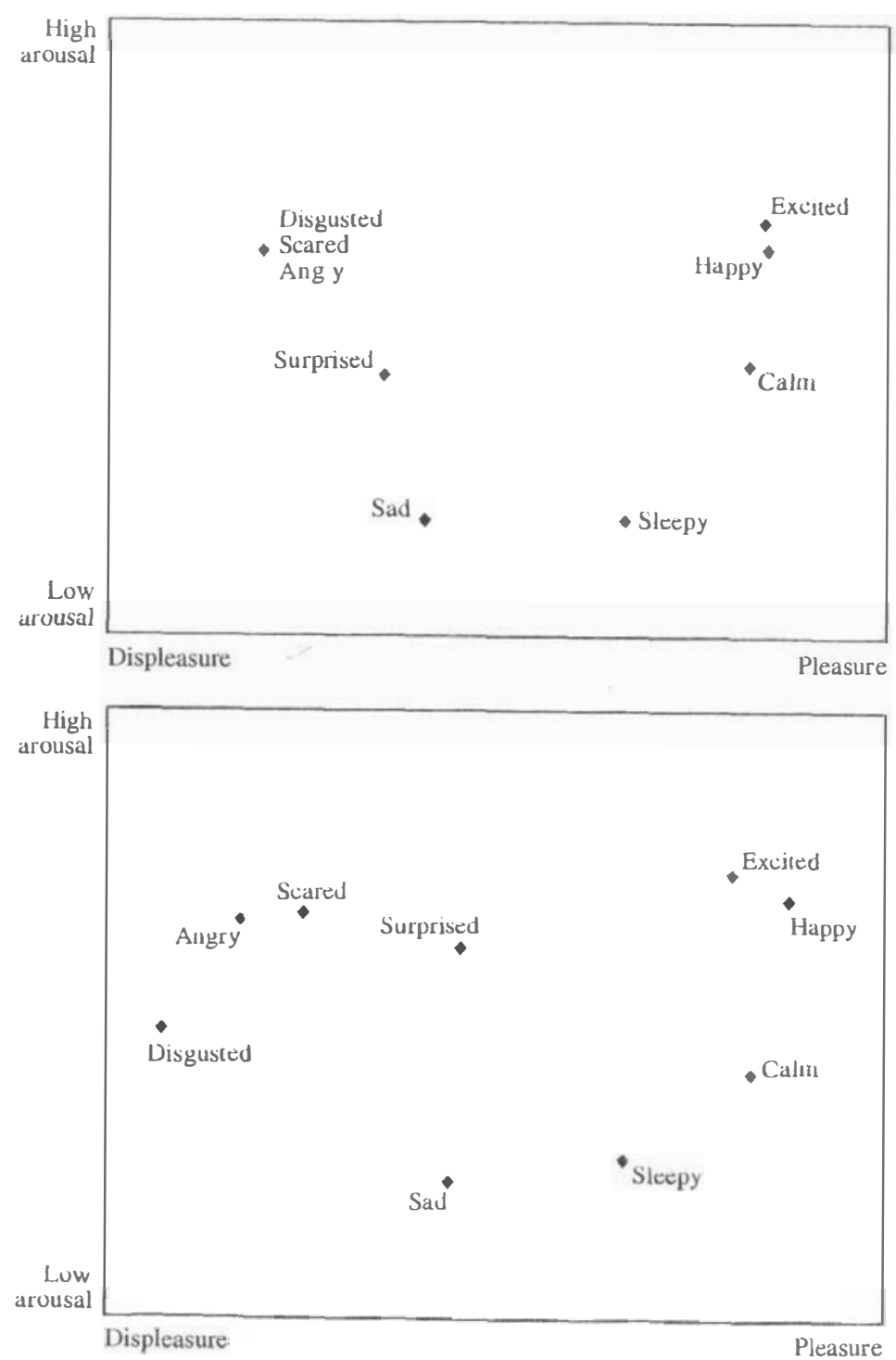

Fig. 4. Multidimensional scaling representation of emotional expressions. Above: Autistic group; below: Comparison group. 
Although the MInS representations for the individuals with autism and the comparison participants form elliptic rather than circular configurations, the two dimensions describing this representation are the same ones as those found in all previous studies: "pleasure vs displeasure" (horizontal axis) and "high vs low arousal" (vertical axis; Fig. 4)

However, there is a gap in the autistic persons' representation in the upper half, which is clue to the "wrong" position of the surprised picture. Because similar results have been found with younger normal children (Bormann-Kischkel et al., 199()), we split the autistic and the comparison group into a younger and an older one (median < 15 years) and performed separate MIDS analyses. While the MDSsolution for the younger comparison group, too, shows a gap in the upper part of the configuration, the data of the older comparison group form a closed, elliptic configuration, with the surprised picure receiving high scores on the arousal dimension. No such shifi occurs for the autistic group, however. Apparently, there was a developmental shift leading to a different evaluation of the surprised face by older children and adults. This shitt, however, did not occur in the autistic group.

Because the stress values of the MIISS indicated no substantial difference between the two- and the three-dimensional solutions for the autistic group, we also looked at the three-dimensional solution. The third dimension could not be interpreted in terms of emotional concepts, but was a reflection of morphological features. At one end of the axis, there were all the pictures with an open mouth and exposed teeth, whereas expressions with lips closed lay at the other end. Even expressions which are contradictory in their hedonic value but similar with regard to exposed teeth, such as happy and angry, were situ ated close together on this axis. We therefore suggest that this dimension reflects the influence of perceptual similarity on the subjects' choices of emotional expressions. No such dimension was substantiated for the comparison group, however. To our knowledge, there is no way of testing the difference in the reduction of stress between both groups. We can therefore report this finding as an interesting trend only.

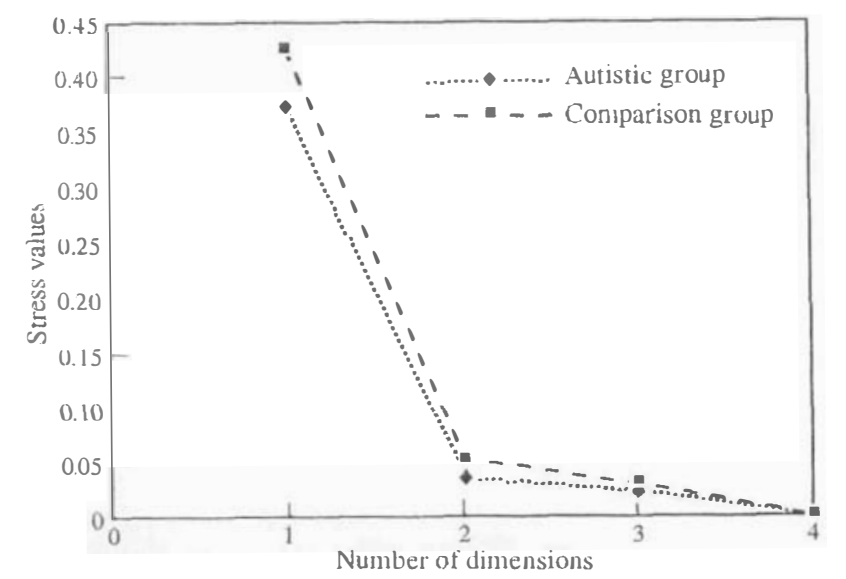

Fig. 5. Stress values of the muldidimensional scaling solutions for the coluurs.
Structure of colours

The same results as in the pilot study were obtained for both groups. There is avery clear indication for a two-dimensional solution from the stress values of both groups (Fig. 5).

The configuration obtained by the MIDS are nearly perfect circles with the dimensions "red vs green" and "blue vs yellow" for both groups (Figs. 5 and b).

Because of the distinct stress reduction from the one- to the two-dimensional solution, no three-dimensional solution was interpreted.
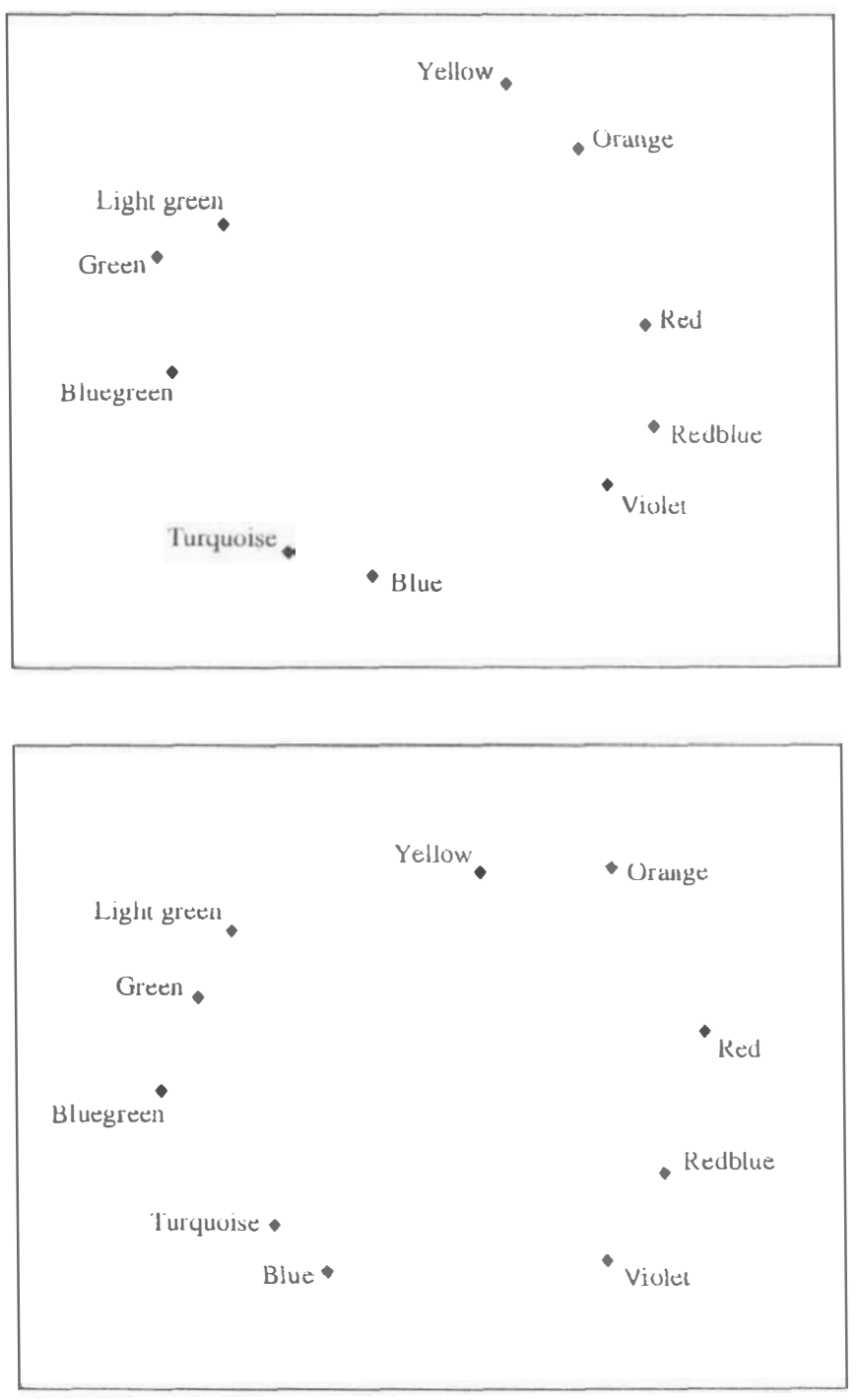

Fig. 6. Multidimensional scaling representation of colours. Above: Autistic group; below: Comparison group. 


\section{Discussion}

Before turning to the task under study we consider it necessary to discuss the appropriateness of our comparison group and of the control task. The rationale behind our selection of participants for the comparison group was to control for factors that in addition to the diagnosis of autism might influence the task behaviour. We considered age, cognitive endowment and a history of developmental disturbances as the most critical ones. Because of the variation of age and IQ in our autistic sample it was impossible to confine the control group to members of one diagnostic group. Admittedly, ou procedure has the disadvantage of obscuring within-group variation. The same argument holds true for the autistic group, however, because the occumence of autism is considered to be determined by multiple factors. As long as there is no agreenemt on nosologically founded subgroups in autism we see no other way to deal with this problem.

It may also be questioned, whether the recognition of colours constitutes an appropriate control condition for the recognition of emotional expressions. This is true, for instance, with regard to the lack of a risuos-spatial factor: Other arguments against the use of colours might include their low level of abstraction and the intense amount of training that subjects receive on colour matching but not on emotions matching. The latter objection can be dealt with quite easily: colour matching games and tasks are common with all young children, both normal and handicapped, and do not constitute a training programme exclusive for autistic children. Therefore, one would not expect a specific advantage for this group on colour matching

The argument that colours are of a lower conceptual level than emotions cannot be refuted. Because we did not use fully satiated colours, this task was not trivial for the subjects. But matching an ochre chip to the term "yellow" can still be considered as a primarily perceptual, not a conceptual task. This would indeed be a serious problem, if it led to a ceiling effect. However, this was not so, as we shal point out.

In devising the experiment, we were aware of these problems but decided to keep colours as a control experiment, because there also are parallels between emotions and colours. In both tasks, a correspondence between verbal concepts and visual stimuli from a particular domain has to be formed by the subject. Similar developmental comrses have been suggested for colours and for emotions: At the begimning of life, the colour space is thought to be divided into only a few areas, with gradually increasing differentiation (e.g. Berlin \& Kay, 1969). In very much the sane way, the development of emotional concepts has been hypothesized. Very young children are hought to discriminate emotions according to pleasantmess and arousal only. I ater on, they will develop more differentiated, adult-like categories labelled "happiness", "anger", "sadness", etc. (Bullock \& Russell, 1986). The data from our pilot studies support these developmental similarities. Finally, we did not find any other material paralleling the emotion task in terms of providing prototypica class members for a given concept, and of being structured in a two-dimensional, circular configuration. We therefore think that despite some differences, colours qualify as an appropriate control condition.
We found a clear deficit in the recognition of emotions in our sample of highfunctioning persons with autism. This impairment was specif ic to emotion concepts and did not extend to colour concepts. Because of the multiple control conditions in studying an age as well as IQ matched comparison group and in partialling out the effects of verbal development we think that it is un likely to attribute the results to a cognitive-intellectual deficit or a difference in verbal-conceptual ability. No differences either between high-functioning children with autism and normal children in their general cognitive-semantic abilities were found by Tager-Flusberg (1985a,b).

The Emotion Iask and the Ciolour Iask differed in difficulty, with the Emotion Task being more difficult for both groups. This would be a severe problem, if it resulted in a ceiling effect on the Colour Task. Although the distribution of scores on the Colour Task (Fig. 2) does not support this, it has to be admitted that a control task of comparable difficulty would have been better.

The autistic participants' results are above chance on all but one emotion term (entsetzt [terrified]), which, however; was also poorly understood by the comparison group. This means that high-functioning persons with autism do not suffer from a complete inability to understand emotions but that they are less efficient as compared to a group of non-autistic persons of similar age and intellectual development. As in manyouher studies, the overall size of the effect in the recognition of emotions is small. As we pointed out in our Introduction, this may indicate impairment as opposed to complete inability. On the other hand, it can also mean that the autistic group included some individuals who were mable and others who were well able to perform the task. As can be seen from Fig. 1, the distribution of scores of the autistic group is very similar to that of the comparison group, but with a lower mean. This validates our interpretation of an impairment in the recognition of facial expression in individuals with autism.

Another difference between groups in the recognition of facial expression was revealed by the multiple regression analysis. Individuals with autism were influenced only by their verbal abilities on the Emotion Task, while the comparison group was strongly influenced by their IQ. Perhaps, this pattern indicates that the comparison group used more reasoning strategies such as deduction or exclusion strategies in matching the pictures to emotion terms, while the individuals with autism resorted more to word-picture associations.

Looking at the performance at single emotion terms, the participants with autism exhibit specific deficits on the concepts erstaurt [astonished], zornig [angry], and less pronounced for überrascht [surprised], erschreckt [scared] and wütend [angry]. With the exception of zornig and wütend, these emotion terms can be interpreted as more complex ones with regard to cognitive involvement. These are all concepts expressing a mismatch between an individual's expectation and an environmental event, which is externally controlled. For instance, in order to be surprised one needs to have a notion that an event is unusual in a given situation, and it cannot be internally controlled. This provides an interesting link to the results from Capps et al. (1992). They, too, found the impairment to be greater in complex emotions with an external locus of control (such as embarassment). These emotions require knowledge of situations and social scripts, in which autistic people are also impaired 
(Fein et al. 1992). tmotion terms such as surprise, astonishment, etc. are therefore not only expressions of an inner feeling state but they also require knowledge about an event. This notion of the "aboumess" of an emotion is reminiscent of the ability to form second-order representalions, which are thought to be prerequisites for a "theory of mind". ( )ne could argue that emotional expressions which are not mere signs of an inner experience but relate to an event outside of an individual might be precursors of a "theory of mind" in an emotional mode (see also Bormann-Kischkel, Amorosa \& von Benda, 1993).

These explandions do not apply of the impaired comprehension of zornig [angry] and wietend [angry] by the autistic subjects. It could be that they have not yet acquired the correct meanings of these words. However, there is no indication that these terms are less frequent or more unusual in German than many of the other emotion terms. Maybe, the visual features of the photo were not properly recognized by many individuals with autism. Although picture $\mathrm{E}$ was correctly recognized in on pilot study, it is somewhat atypical, as the model shows an openmonthed angry face, making it thus a very intense expression. Perhaps anger of this intensity has never been observed in reality by many people with autism and thus was not properly recognized by them. Given their general lack of interest in other people's behaviour in movies, etc. they are unlikely to have leamt it incidentally, which may have been the case with the comparison subjects.

With regard to the performance of single colour terms, no differences between groups emerged except for gelbgrïn [yellow-green]. This colour term was more of ten associated with the standard chip by the autistic subjects than by the comparison subjects. We have no explanation for it and consider it a chance result.

Despite the differences in amount of correct responding, the groups were quite similar in the structures underlying their responses to the emotion terms. Just as all other groups studied, people with autism structured emotion concepts by degree of pleasure or displeasure and by amount of arousal. Although these two dimensions provide the best fit for the data, it can be seen that, for the autistic group, no closed pattern emerged, as was the case for the comparison group. For the autistic group, however, there is a gap in the upper half of the configuration. This is mainly due to the "wrong" position of the "surprised" picture, which has low scores on arousal and is close to the "sad" and "sleepy" pictures. This was due to a misinterpretation of the surprised face as being tired. Tivelve subjects with autism selected picture $C$ (= surprised) in response to the term müde [tired]. Four of them even made it their first choice. Some autistic persons explained their choice by commenting that the woman in picture (: was yawning. In contrast, only six subjects of the comparison group selected picture $C$ as a response to müde [tired], and only two selected it in the first place. The autistic subjects were obviously focusing on the lower part of the face. A tendency of autis tic children to rely more on the mouth region has already been observed by liangdell (1978). Paramey (personal communication, 1993) and Bormann-Kischkel et al. (1990) found very similar results for the surprised face with normal preschool children. We therefore think that these results reflect a developmental shift in the strategies used for processing facial expressions. This shift is substantiated by the MIDS-solutions of the different age groups, but only for the comparison group.
Two explanations can be put forward to explain these results. Either, autistic children employ scanning strategies, which focus for one reason or another on the mouth region of a face. This may be of advantage in processing inverted faces (e.g. Langdell, 1978), but leads to errors in emotion recognition. The autistic subjects' deficit would then be attributed to a disturbed visual scanning behaviour Abnormal gaze behaviour has indeed been repeatedly reported for autistic children (e.g. Hutt \& Ounsted, 1970; Hermelin \& O'Connor, 197())

On the other hand, attending only to the mouth region of a face could also be viewed as a "piece-meal", perceptually oriented strategy of processing as opposed to a holistic, conceptual one. Such a strategy could also be responsible for the influence of irrelevant features on emotion recognition, such as hats (Jennings, 1973; Weeks \& Hobson, 1987), wigs (Bormann-Kischkel, 1990) or otherwise perceptual similarity (Ozon off et al., 199l). This interpretation is in line with the results of the three-dimensional MDS-analysis. The third dimension reflects a single morphological feature of the face, which, too, suggests the influence of nonholistic, nonemotional perceptual strategies in the processing of facial expressions.

For normal kindergarten children, we related this influence of perceptua features to very early processes in the recognition of facial expressions (BormannKischkel et al., 199()). Very young infants discriminate between different expressions of a face only on the basis of perceptual features, not of emotional meaning (for reviews: Oster, 1981; Nelson, 1987). However, from 7 months onwards, they begin to exhibit a conceptual understanding of emotional expressions (e.g. Bühler \& Hetzer, 1928; Caron, Caron \& Myers, 1985). From our data, we camnot conclude whether the autistic subjects' behaviour in our experiment is a "left-over" from infantile processing strategies, which perhaps is in terfering with a more advanced conceptual strategy, or whether it reflects a deviant mode of processing. But given the importance of einotional expressions from early on in life in so many areas as parent-child interaction, attachment behaviour, or communicative development, a deficit in the recognition of emotional expression should not be too readil refuted as an explanation for the disturbed social and cognitive developmen in autism, even though it may not appear to be of crucial importance at a later age.

Another implication of our results is that processes involved in the recognition of facial expressions should be studied further: Not only conceptual, but also visuospatial or perceptual factors seem to play a role. It would, for instance, be interesting tostudy the relative contribution of conceptual and perceptual features in autism. This could be done by varying the perceptual features of a face by including, for instance, pictures with nonsense facial patterns.

It should be kept in mind that our results are limited to a subgroup of highfunctioning autistic children and adolescents. Even our simple experimental procedure was too demanding for very young and for low-functioning autistic children. However, questions arising from these results can also be tested with them. Discrimination learning paradigms and testing for generalisation along the dimensions of pleasantness and arousal or of perceptual similarity could provide appropriate procedures 
Acknowledgements - We ale indebied wo all the childsen dud parents who agreed to participate in this study. We also thank PI) I) I. Hedwig Amorusa, Heckscher klinik, Munich (Solln), Dr. Elvira Muchitsch tutistenberatungszentrum, Vienna, and Dr. Nicosia Nieß, Regionalverband "Hilfe für autistische Menschen", Munich, for their manifold help. The support of Prof. Helmut Lutesch, Universita Regensburg, and of the Deusche Forschungsgesellschaft (I)FG), grant L.u 291/5-1, is gratefully acknowledged.

\section{References}

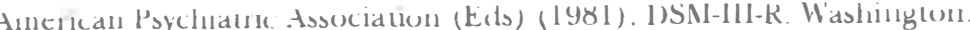

Berlin, B \& Kay P (1969). Basic color termes. Berkley, Cit: University of Calitornia Psess

Bormann-Kischkel, C. (1990). Erkennen autistische Kinder Personen und Emotionen? Regensburg: Ro V'erlay.

Burmann-Kischkel, C., Amurusa, H. \&. von Benda, U. (1993). Is there an association between emotion feelings and emotional signs in autism? Acta Paedopsychiatrica, 56, 1-9.

Burman-Kischkel, C.,Hildebrand-Pascher, S. \& Stegbaner, G. (1990). The development of emotiona concepts: a replication with a German sample. International Journal of Behazioural Development $13,355-372$.

Bühler, C. \& Hetzer, H. (1928). Das erste Verständnis füı Ausdruck in ersten l.ebensjahr [The firs comprehension of expression in the tirsc year of life]. Zeilschrift für Psychologie, 107, 50-61.

Bullock, M. \& Russell, J. A. (1984). Preschool children's interpretation of facial expressions of emotion. International Journal of Behavioural Development, 7, 193-214.

Bullock, M. \& Russell, J. A. (1985). Further evidence on preschoolers' interpretation of facia expressions. International fournal of Behavioural Development, 8, 15-38.

Bullock, M. \& Russell, J. (1986). Concepts of emotion in developmental psychology. In: C. E. Izard *. P. B. Read (Eds), Measuring emotions in infants and children, Vol. II (pp. 203-237). Cambridge: Cambridge University Press.

(Capps, L., Yirmiya, N. \& Sigman, M. (1992)). Understanding of simple and complex emotions non-retarded children with autism. foumal of Child Psycholugy and Psychialty, 33, 1169-1182.

Caron, R. F., Caron, A. J. \& Myers, R. S. (1985). Do infants see emotional expressions in static faces? Child l serelopment, 56, 1552-1560

Dvorine, 1. (1963). Lhorine pseudo-isochromalle plates. New Y'ork: Harcourt, Brace \& Work

Ekman, P. \&. Friesen, W' (1975). Pictures of facial affect. Palo. Alto: Consulting Psychologists Press.

Fein, 1)., Lucci, 1)., Braverman, N.\& Water house, I. (1992). Comprehension of atfect in context in children with Pervasive Developmental Disorders. Journal of ('hild Psychology and Psychiatr $33,1157-1167$.

Heider, E. R. (1971). "Fucal" colur areas and the development of color names. DevelopmentalPsycholog $4,4+7-455$.

Hermelin, B. \&. (1)Connor, N. (1985) ) 1 .ugicu-affective states and nonverbal language. In E. Schople \&. G. B. Mesibov (Eds), Communication Problems in Autism (pp. 283-309). New York: Plenun Publishing Corporation.

Hemelin, B. \&.O'Connor, N. (1970). Psychulugical experiments with autisluc chaldren. Oxtord: Pergamo Press

Hobson, R. P. ( 1991 ). Melludulugical issues tor experinuents on antistic individuals' perception an understanding of emotion. Joumul of ('hild Psychology and Psychiatry, 32, 1135-1158.

Hobson, R. P., (Ouston, I. \&. I.ee, A. (1988). What's in a face? The case of autism. British Joumal of Psychulogy, 79, $+41-453$

Huu $C$. Ounsted, C. (1970) Gace aversion and its significance in childhoud autism. In: S.J. Hut \&. C. Hutt (Eds). Behaviou Stuclies in Psychiatry (pp. 103-120). Oxford: Pergamon Press.

Indow, T. (1988). Multidimensional studies of Munsell color solid. Psychological Rerieu, 95, 456-470

emnings, W. B. (1973). A study of the preference for affective cues in autistic children. Dissertation Memphis: State [ niversity.

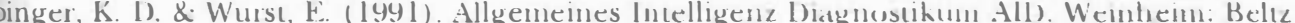
Test Gesellschsaft (3rd edition)

dell, T. (1978). Recognition of faces: a n approach to the study of autism. fournal of C.hild Psycholegv and Psychiatry, 19, 25.5-268.

son, C. (1987). The recognition of facial expressimes in the lirst wo years of life: mechanisms of development. Child Development, 58, 889-909.

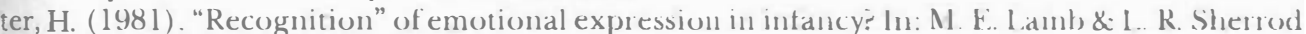
(Eds), Infant social cognition: empirical and theoretical considerations (pp. 85-125). Hillsdale N.]. Erlbaum.

onoff, S., Pennington, B. F. \& Rogers, S. I. (1991). Executive function deficits in high-functioning autistic individuals: relationship to theory of mind. Journal of ('hild Psychology and Psychiatry, $32,1081-1105$.

Pramey, G. (1993). Personul commuricution. Münster, Iagung experinentell arbeitender Psycholugen (TeaP)

Raven-Matrizen-Test (1987). Deutsche Bearbeitung von H. Kratzmeier und R. Horn [Raven Matrices. German version by H. Kuatzmeier and R. Horn] (2nd edition). W'einheim: Beltz Verlag.

osch, E. (1975). The nat.ure of mental codes for color categories. Journal of Experimental Psychology: Human Perception and Performance, 1, 3(1)3-324)

Roth, 28 Hue Test according to Fansarorth-Munsell. Paris: L .uneau (Oph hitalmologie

ussell, J. A. (1983). Pancultural aspects of the human conceptual organization of enustons fournal of Personality and Social Psychology, 45, 1281-1288

(ter, M. (1978). Diagnosis and definition. In M. Rutter \& E. Schopler (Eds), Autlsm (pp. 1-25). New York: Plenum Press.

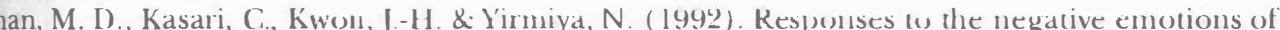
others by autistic, mentally retarded, and nomal childien. ('hild Development 63, 796-807.

ager-Flusberg, H. (1985a). The conceptual basis for referential word meaning in children with autism. Child Development, 56, 1167-1178.

ger-Flusberg, H. (1985b). Basic level and superordinate level calegorilation by autistic, mentally retarded and normal children. Journal of Experimental (Chile Psycholog, 40, 450-469.

eeks, S. J. \& Hobson, R. P. (1987). The salience oft acial expression for autistic children. fournal of Child Psychology and Psychiatry, 28, 137-152.

rmiya, N., Sigman, M. I)., Kasari, C. \& Mundy, P. (1992). E.mpathy and cognition in high-functioning children with autism. Child Development, 63, 150-160)

\section{Appendix}

\section{Emotion terms}

fröhlich

glücklich

sich über eine

Überraschung

freuen

erstaunt

erschrecki

entsetzt

wütend

zornig

sich grausen

sich ekeln

traurig

müde

gelangweil

friedlich

\section{Colour term}

rot

orange

braun

yelb)

gelbyrün

hellgrün

grün

blaugı ü

türkis

hellblaı

blau

violet

viole

lila

rosa eci

orange

or ange

yellow

yellow-gicen

light green

green

blue-grees

turquoise

light blue

blue

violet

ed-blue

pink 